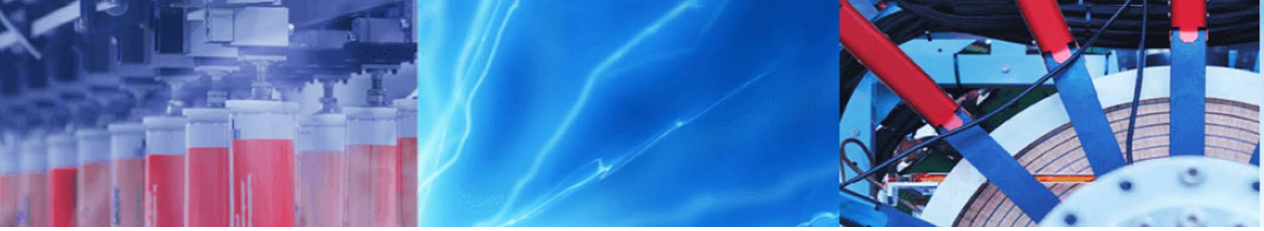

Short Communication

\title{
Experimental and numerical studies of skirted hexagonal footings on three sands
}

\author{
Adarsh Thakur $^{1}$ (D) $\cdot$ Rakesh Kumar Dutta ${ }^{1}$
}

Received: 30 December 2019 / Accepted: 12 February 2020 / Published online: 25 February 2020

(c) Springer Nature Switzerland AG 2020

\begin{abstract}
The paper presents an experimental and numerical study to determine the ultimate bearing capacity of unskirted, singly and doubly skirted hexagonal footings on sands $S 1\left(D_{10}=0.14\right), S 2\left(D_{10}=0.45\right)$ and $S 3\left(D_{10}=1.45\right)$. Laboratory plate load tests were conducted in this connection on the unskirted, singly and doubly skirted hexagonal footings on three sands placed in a test tank at a relative density of $30 \%$. The length of the skirt ranged from $0.0 B$ to $1.5 B$. The results show that the bearing capacity for the skirted hexagonal footings on sand S3 was higher, followed by sands S2 and S1. However, the results revealed that the numerically obtained bearing capacity was comparable with the one obtained experimentally for the hexagonal footings on three sands. In addition, the experimental findings confirmed numerical results obtained with an average deviation of $1 \%$. Double-skirt provision provides marginal improvement in the bearing capacity compared to singly skirted footings. The pattern of failure produced supports observations of the bearing capacity of the unskirted, singly and doubly skirted hexagonal footings on three sands.
\end{abstract}

Keywords Bearing capacity · Sands · Hexagonal footing $\cdot$ Singly skirted $\cdot$ Doubly skirted

\section{Introduction}

In the practice of geotechnical engineering, the shallow footings such as square, circular, strip and rectangular shapes are in use. But there may be situations in which, due to economic and architectural reasons, specific geometries such as cross, $\mathrm{T}, \mathrm{H}$ and hexagonal footings are required at a particular site. Such footings are called multiedge footings, as stated by Jaiswal and Sengupta [1] and Davarci et al. [2]. The foundation design requires calculating the footings' bearing capacity to a reasonable accuracy in order to affect the economy as a whole. However, various unconventional geometries were sometimes required for the shallow footings from an economic and architectural point of view. A numerical analysis was performed by Ghazavi and Mokhtari [3] to analyse the behaviour of multi-edge shallow footing on sand using FLAC 3D. The laboratory tests on multi-edge footings were performed by Davarci et al. [2] and reported that multi-edge footing performance was higher than that of square footing with the same width. A multi-edge $\mathrm{H}$-shaped skirted footing laboratory model test was conducted by Gnananandarao et al. [4] and reported that the multi-edge $\mathrm{H}$-shaped skirted footing improved bearing capacity compared to the square skirted footing. The paper presents a detailed laboratory study on model unskirted, singly and doubly skirted hexagonal footings on three sands followed by a three-dimensional analysis of the same using finite elements. In addition, the numerical results were compared with the test results for the hexagonal unskirted, singly skirted (SS) and doubly skirted (DS) footings.

Adarsh Thakur, adarshneggi@gmail.com | 'Department of Civil Engineering, National Institute of Technology, Hamirpur, Himachal Pradesh, India. 


\section{Background}

In recent years, experimental research on skirted footings such as strip [5-7], square [4, 8-12], circular [6, 13-23] and rectangular [12], subjected to vertical or inclined loads, has been reported. Numerical studies on skirted footing such as strip [6], square [10] and circular [6] were reported in the literature. The above studies concluded that (1) skirted footings improve the bearing capacity with an increase in the footing/skirt roughness, (2) square skirted bearing capacity was close to the same size pier foundation bearing capacity, (3) circular skirted bearing capacity at the same depth of the skirt was higher than the skirted strip and (4) skirted footings on loose sand were more effective than those on medium or dense sand. It was reported by $[2,3]$ that unusual geometries of the footings such as $\mathrm{H}_{1}+$ and $\mathrm{T}$ could also improve the bearing capacity in comparison with the conventional geometry (square, rectangular, circular). Given the advantages of adding skirts to traditional footings, [4] recently reported a multi-edge $\mathrm{H}$-shaped footing experiment with and without skirts on sand, varying the relative density and normalised skirt depth from 30 to $60 \%$ and 0.25 to 1.5 , respectively, and confirmed the findings of [2] for unskirted multiedge footing. In addition, the skirts are attached to the periphery of the geometry of the footing as evident from the experimental and numerical study reported above in the literature to increase the bearing capacity. Nonetheless, the use of unusual (hexagonal) geometry of skirted footings with a vertical concentric load has not yet been researched in the literature. Therefore, this paper presents the laboratory results obtained from the model hexagonal unskirted, singly and doubly skirted footings on three sands, and the same was compared to the numerical study results.

\section{Materials used and experimental methods}

Three sands (called S1, S2 and S3) are used in this investigation. The sands (S1, S2 and S3) granulometry curves are shown in Fig. 1. Sands S1, S2 and S3 had an effective size and specific gravity of $0.14,0.45,1.45$ and 2.68 , $2.67,2.67$, respectively. The consolidated drained triaxial experiment ( $38 \mathrm{~mm}$ dia. and $76 \mathrm{~mm}$ height) on sands $\mathrm{S} 1, \mathrm{~S} 2$ and S3 was performed at a relative density of $30 \%$. Applied cell pressure ranged from 25 to $200 \mathrm{kPa}$. For sands S1, S2 and S3, the angle of friction calculated was $33.37^{\circ}, 36.52^{\circ}$ and $39.47^{\circ}$, respectively. It is worth mentioning here that [12] and [24] also obtained the

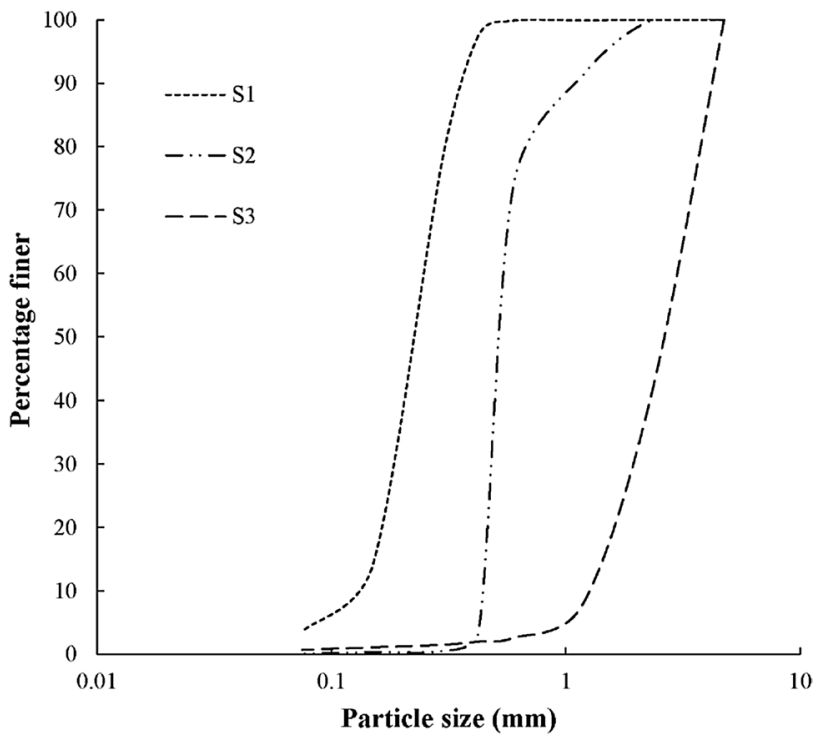

Fig. 1 Granulometry curves of sands S1, S2 and S3

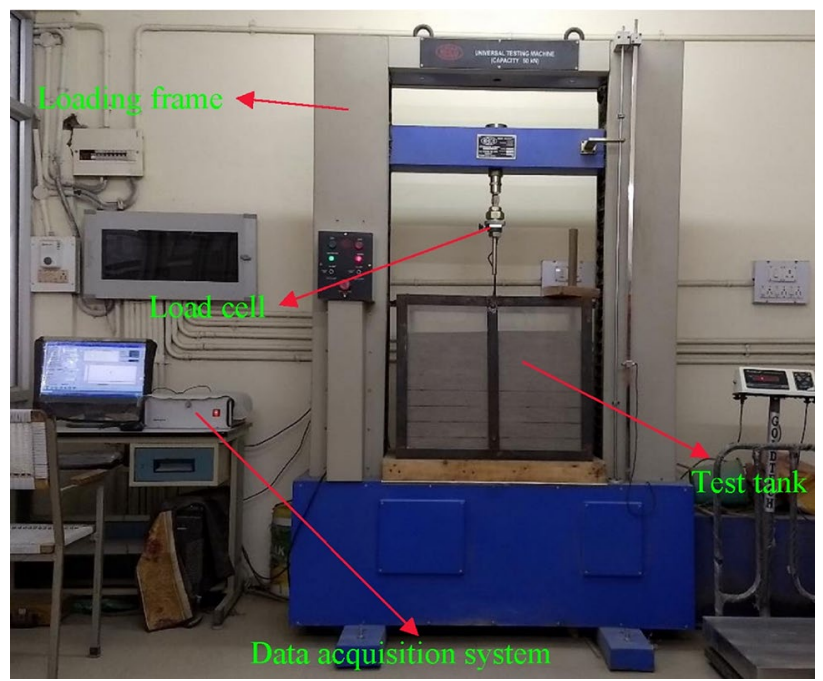

Fig. 2 Experimental test set-up

friction angle of the sand as $33.4^{\circ}$ and $32.5^{\circ}$, respectively, to a relative density of $30 \%$. The Young's modulus (corresponding to $50 \%$ of the peak stress) for sands S1, S2 and S3 obtained from the stress-strain curves was 4.8 $\mathrm{MPa}, 5.2 \mathrm{MPa}$ and $5.5 \mathrm{MPa}$, respectively, to a confining pressure of $50 \mathrm{kPa}$. The test set-up (Fig. 2) consists of a test tank $(700 \mathrm{~mm} \times 450 \mathrm{~mm} \times 600 \mathrm{~mm}$, constructed from the perspex sheet and further stiffened with a steel frame), pluviator, loading mechanism and data acquisition system to study the pressure-settlement ratio behaviour of unskirted/skirted hexagonal (singly and doubly) footings on sands. The footings with and without skirt are made from a locally available iron sheet of 


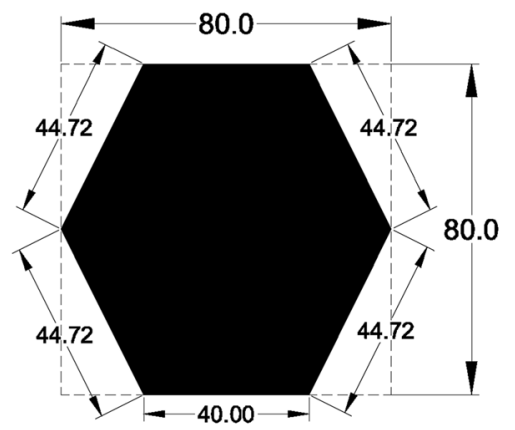

(a) (All dimensions in ' $m m$ ')

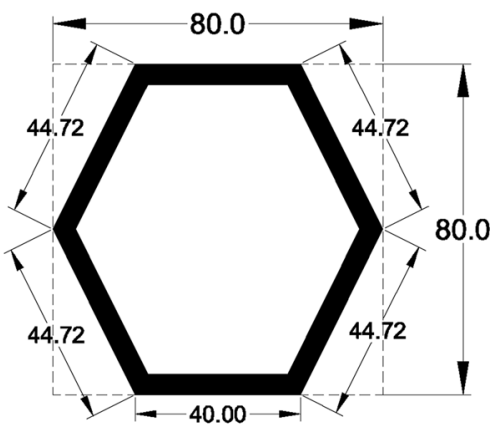

(b) $\mathrm{B}=80 \mathrm{~mm}$

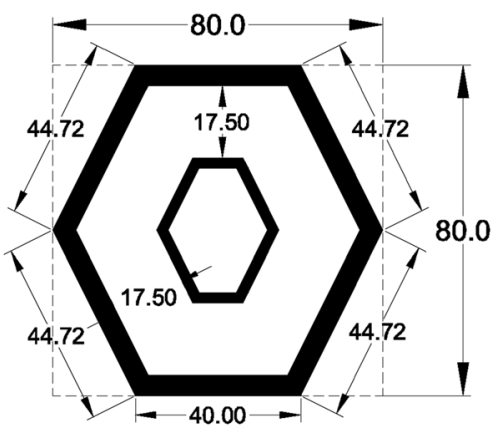

(c)

Fig. 3 Plan view of hexagonal footing a unskirted (thickness $10 \mathrm{~mm}$ ), b singly skirted (thickness of skirt $5 \mathrm{~mm}$ ) and $\mathbf{c}$ doubly skirted (thickness of skirt $2.5 \mathrm{~mm}$ )

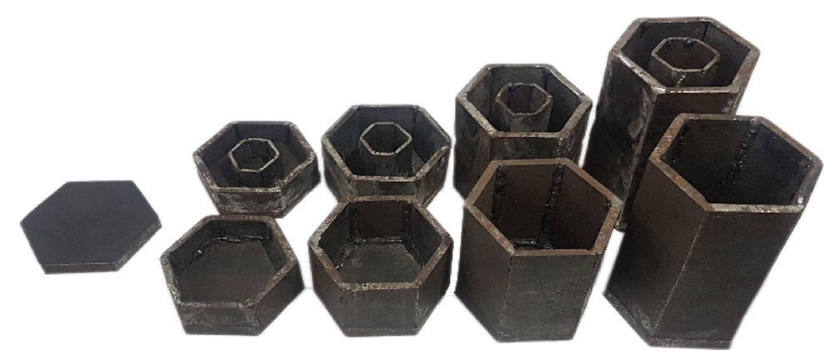

Fig. 4 Hexagonal footings unskirted, singly skirted and doubly skirted

$10 \mathrm{~mm}$ thick. A square's outer dimension was selected as $80 \mathrm{~mm} \times 80 \mathrm{~mm}$. As shown in Fig. 3, hexagonal footing was built inside this square. This hexagonal footing's outer skirt was made of a 5-mm-thick iron plate and welded around its outer edge for the singly skirted footing. For the doubly skirted footing, another skirt made of a $2.5-\mathrm{mm}$-thick iron plate was welded at a distance of $17.5 \mathrm{~mm}$ around the perimeter from the inside of the outer skirt as shown in Fig. 4. The outer and inner lengths of the skirt ranged between 0 and $120 \mathrm{~mm}$ in both the cases. The test tank size was maintained to prevent the restricting effects that would otherwise result in additional stresses and strains being generated in the sand. The tank was filled with eight equal layers of $60 \mathrm{~mm}$ each up to a height of $480 \mathrm{~mm}$ to prepare the sand bed. The skirted footings were more effective in loose sand as reported in the literature $[4,6,18,20]$. In view of this, all experimental investigations were conducted at a relative density of $30 \%$ and were conducted up to a settlement ratio $(s / B)$ of $20 \%$, where ' $B$ ' is the width footing. The weight of the sand corresponding to a given relative density was obtained by knowing the unit weight and the volume of the soil for the preparation of each layer. The sand was then poured to fill the layer from a constant height and compacted by hand

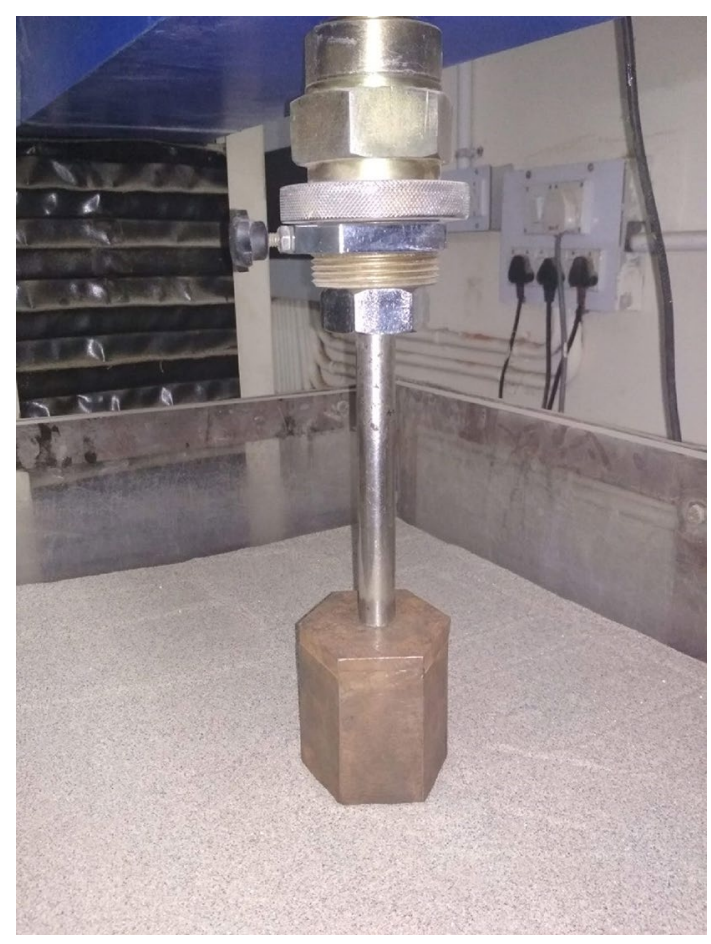

Fig. 5 Placement of skirted footing on sand bed

using a $6 \mathrm{~N}$ wooden rammer. The unit weight of sands $\mathrm{S} 1$, $\mathrm{S} 2$ and S3 was maintained in the test tank as $14.38 \mathrm{kN} /$ $\mathrm{m}^{3}, 14.89 \mathrm{kN} / \mathrm{m}^{3}$ and $15.15 \mathrm{kN} / \mathrm{m}^{3}$, respectively. The test was carried out on the prepared sand bed using a load cell and strain-controlled loading frame of capacity $5 \mathrm{kN}$ and $50 \mathrm{kN}$, respectively. All tests were conducted using a strain rate of $0.24 \mathrm{~mm} / \mathrm{min}$. The model footing was put on the surface of the prepared bed to test the unskirted hexagonal footing. The plunger was brought into contact with the metal ball positioned at the centre of gravity on top of the hexagonal footing, and the load test was then conducted. In the case of singly and doubly 
hexagonal skirted footing after [4, 12], the footing was introduced into the sand (Fig. 5) by adding the load until the footing base begins hitting the sand's top surface. As stated by Khatri et al. [12] and Gnananandarao et al. [4] for the footings, heaving was not observed around the footing following this procedure. This means that the marginal sand densification around the periphery of the skirt may not have a significant impact on the footing's ultimate bearing capacity. Similar to the unskirted hexagonal footing, the study then proceeded. Each test was performed three times, and during each test, almost similar set of results was obtained and therefore three tests were supposed to be sufficient to reproduce the repeatability of the results obtained. The sand layer involved in failure was removed and replaced by fresh sand at the end of each test, and the depth of this replacement was taken as $3 \mathrm{~B}$ below the edge of the skirts as per $[4,10,12]$.

\section{Numerical study}

\subsection{Problem definition and finite element model}

A rigid hexagonal footing, singly and doubly skirted, is placed over three sands (S1, S2 and S3) separately with a horizontal ground surface. Figure 3 shows the plan view of the footings. The footing is subjected to concentric vertical downward load. It was intended to determine the ultimate bearing capacity $\left(q_{\mathrm{u}}\right)$ for: $(1) 33.37^{\circ}, 36.52^{\circ}$ and $39.47^{\circ}$ friction angles for sands $S 1, S 2$ and $S 3$, respectively, (2) nondimensional skirt depth-to-width ratio $\left(D_{s} / B\right)$ varying from 0 to 1.5 and (3) two different types of hexagonal skirted footing (singly and doubly) as shown in Fig. 4. Past authors have done numerous works on traditional skirted footings (strip, circular and square) but have not yet studied singly and doubly skirted hexagonal footings. In order to study the behaviour of unskirted, singly and doubly skirted hexagonal footing on three sands, three-dimensional finite element analysis was performed. Parameters such as saturated unit weights S1 $\left(18.83 \mathrm{kN} / \mathrm{m}^{3}\right), \mathrm{S} 2\left(19.12 \mathrm{kN} / \mathrm{m}^{3}\right)$, S3 $\left(19.29 \mathrm{kN} / \mathrm{m}^{3}\right)$, unsaturated unit weights S1 $(14.38 \mathrm{kN} /$ $\left.\mathrm{m}^{3}\right)$, S2 $\left(14.89 \mathrm{kN} / \mathrm{m}^{3}\right)$, S3 $\left(15.15 \mathrm{kN} / \mathrm{m}^{3}\right)$, Poisson's ratio S1 $(0.3), \mathrm{S} 2(0.3), \mathrm{S} 3(0.3)$ and dilation angle $(\phi-30) \mathrm{S} 1\left(3.37^{\circ}\right)$, S2 $\left(6.517^{\circ}\right)$, S3 $\left(9.47^{\circ}\right)$ were used for modelling. The Young's modulus and Poisson's ratio of the iron sheet considered for the modelling were $210 \mathrm{GPa}$ and 0.2 , respectively. It is pertinent to mention here that the Poisson ratio of cast iron is in the range of 0.2 to 0.26 . Hence, a lower value of 0.2 is adopted for modelling. The sand moduli S1 (4.8 MPa), S2 (5.2 MPa) and S3 (5.5 MPa) corresponding to a $50 \mathrm{kPa}$ confining pressure adopted are not far apart and were considered to be constant with depth for numerical modelling as per [10] to compensate for smaller value of moduli at relatively shallow depths. However, further study is recommended for linearly increasing sands moduli with depth. A Mohr-Coulomb model was used for the analysis as it represents a 'first-order' approximation of the sands behaviour by estimating a constant average stiffness, resulting in faster computations to obtain a first estimate of deformations, whereas the other soil hardening models take more computational time due to the formation of material stiffness matrix which get decomposed in every step as reported in Plaxis 3D Foundation material models manual version 1.5. Through taking into account the variations of different parameters, a validated numerical model, including parametric variations, will solve the problem of conducting large numbers of laboratory experiments. The following sections define the parameters adopted for this work on the various aspects of numerical modelling.

\subsection{Boundary conditions and finite element meshing}

Figure 6 displays the typical numerical model for the hexagonal skirted footing on sand. It is worth noting here that the outer boundary of the numerical model and the footing scale are kept the same as used for the experimental study in order to avoid size or scale effect $[25,26]$. The stress contour ' $0.1 q^{\prime}$ is the maximum relevant isobar, beyond which the stress impact applied is considered negligible. The model dimensions were selected so that the sand model boundaries geometry did not cross the appropriate isobar.

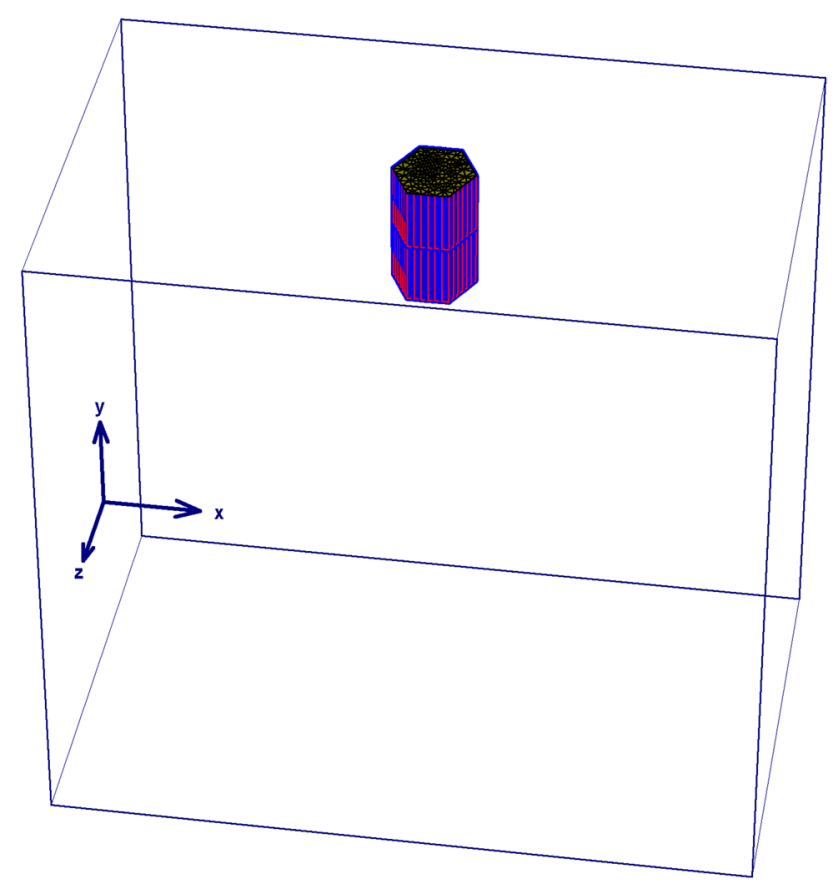

Fig. 6 Numerical model for the hexagonal skirted footing placed on sand 


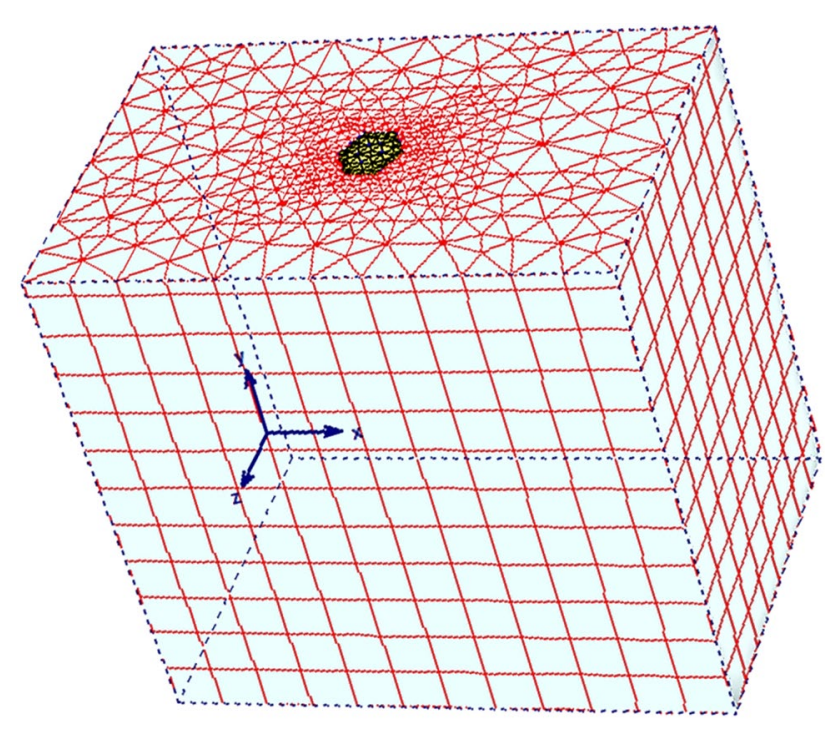

Fig. 7 Standard mesh used for a numerical model

The model was discretised in a smaller number of 15-node wedge elements to perform finite element analysis. Domain meshing is carried out in the PLAXIS 3D program using fully automatic finite elements. Five common meshing schemes are available (i.e. very rough, coarse, moderate, fine and very fine mesh), allowing the user to refine an area, line or point further. Figure 7 shows the standard mesh obtained for a numerical model. A very coarse mesh does not catch the key feature responses of the domain. There are chances of numerical error accumulation in addition to optimally fine meshes, resulting in inaccuracy in the data obtained as reported by Acharyya and Dey [27]. Nonetheless, very fine meshing takes considerable time to determine the optimal mesh configuration for any simulation. In this study, coarse to fine mesh is used near footing as shown in Fig. 7. The mesh convergence study reveals that increasing the number of elements beyond 8030 does not have any effect on the settlement response of the geometry under consideration. Hence, 8030 to 10,890 numbers of elements with the average element size of $4.9 \times 10^{-3} \mathrm{~m}$ or less have been used in the numerical analysis corresponding to different $D_{s} / B$ ratios. For the boundary conditions, PLAXIS automatically imposes a number of general fixities on the geometry model's boundaries. The model's bottom boundary is fixed in the present study, and the model's ground surface is free in all directions.

\section{Results and discussion}

The work deals with the experimental and numerically obtained bearing capacity of the unskirted, singly and doubly skirted hexagonal footings on three sands.

\subsection{Unskirted, singly skirted and doubly skirted hexagonal footings' bearing capacity}

Figure 8 demonstrates the pressure and settlement ratio plot obtained experimentally and numerically for the unskirted, singly and doubly skirted hexagonal footings on three sands for skirt depths of $0 B, 0.25 B, 0.5 B, 1 B$ and $1.5 B$. The experimentally and numerically obtained ultimate bearing capacity is given in Tables 1 and 2, respectively. It is appropriate to mention here that the bearing capacity was measured on the basis of the $5 \% s / B$ ratio in all cases (experimental and numerical). Table 1 shows that the unskirted hexagonal footing bearing capacity for sands S1, S2 and S3 is $102.36 \mathrm{kPa}, 142.91 \mathrm{kPa}$ and $185.90 \mathrm{kPa}$, respectively. This bearing capacity was raised to $148.94 \mathrm{kPa}, 204.17 \mathrm{kPa}$ and $293.11 \mathrm{kPa}$, respectively, for the singly skirted hexagonal footing at a skirt depth of $1.5 B$ for sands S1, S2 and S3. For the doubly skirted hexagonal footing, the bearing capacity increased further to $155.41 \mathrm{kPa}, 216.51 \mathrm{kPa}$ and $291.67 \mathrm{kPa}$ of sands S1, S2 and S3, respectively, at the same skirt depth. Table 2 shows that the bearing capacity of the unskirted hexagonal footing was $102.11 \mathrm{kPa}, 144.49 \mathrm{kPa}$ and $187.41 \mathrm{kPa}$, respectively, for sands S1, S2 and S3. With singly skirted hexagonal footing at a normalised skirt depth of 1.5 with sands S1, S2 and $\mathrm{S} 3$, respectively, this bearing capacity was increased to $147.46 \mathrm{kPa}, 203.46 \mathrm{kPa}$ and $286.84 \mathrm{kPa}$. The bearing capacity increased to $151 \mathrm{kPa}, 216.10 \mathrm{kPa}$ and $295.35 \mathrm{kPa}$ for sands S1, S2 and S3, respectively, at the same normalised skirt depth for the doubly skirted hexagonal footing. However, the analysis of Tables 1 and 2 shows that the bearing capacity for the hexagonal footings on sand $\mathrm{S} 3$ was higher, followed by sands $S 2$ and $S 1$. This may be due to the higher sand S3 unit weight relative to sands S2 and S1 in the test tank, resulting in higher bearing capacity for the former. Comparing the results of singly skirted and doubly skirted footing as shown in Tables 1 and 2, it is obvious that the bearing capacity for doubly skirted hexagonal footing was marginally higher than for singly skirted footing at all normalised skirt depths and for all the three sands. This is attributed to the fact that the skirts form an enclosure in which the soil is strictly confined and acts as a unit with the overlain footing at the level of the tip of the skirt to transfer the overlain load to the soil. Tables 1 and 2 also show the percentage improvement with respect to unskirted hexagonal footing for the singly and doubly skirted hexagonal footings for three sands at different skirt depths. These tables reveal that the percentage improvement in case of singly skirted hexagonal footing on sands S1, S2 and S3 was $10.68 \%, 9.11 \%$ and $11.89 \%$, respectively, at a normalised skirt depth of 0.25 . For the doubly skirted hexagonal footing, these values increased to $13.19 \%, 11.73 \%$ and $12.07 \%$ for sands S1, S2 and S3, respectively, at the same 


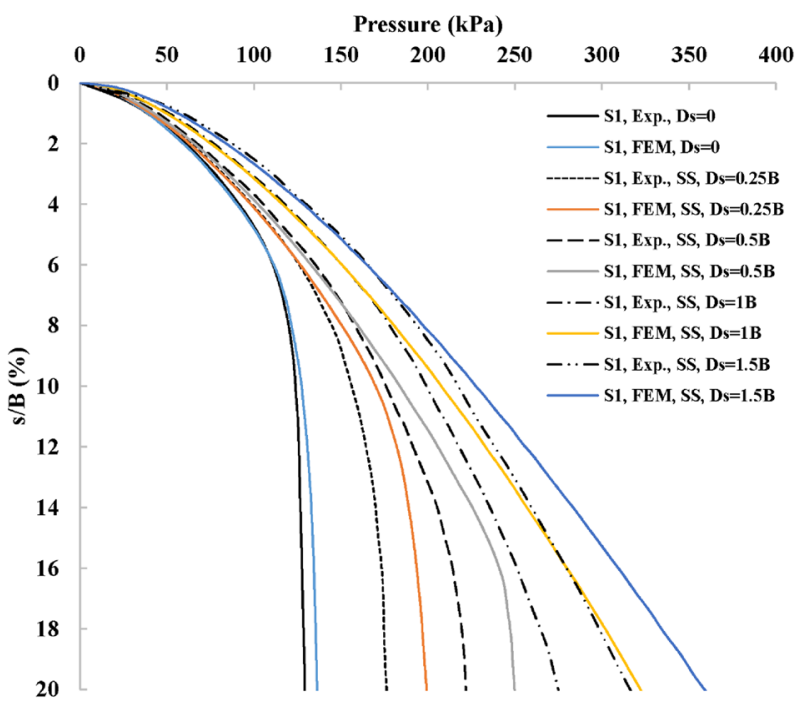

(a)

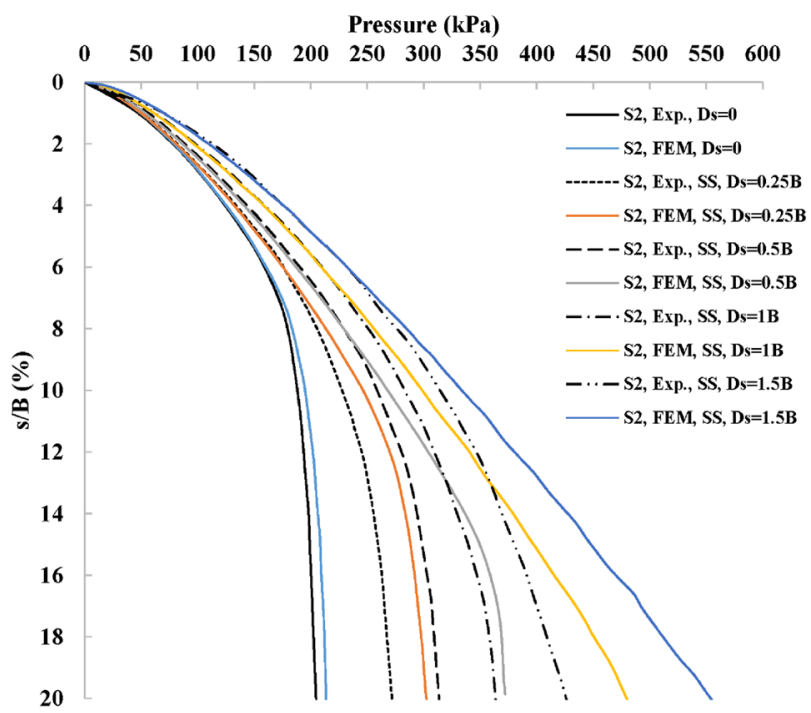

(b)

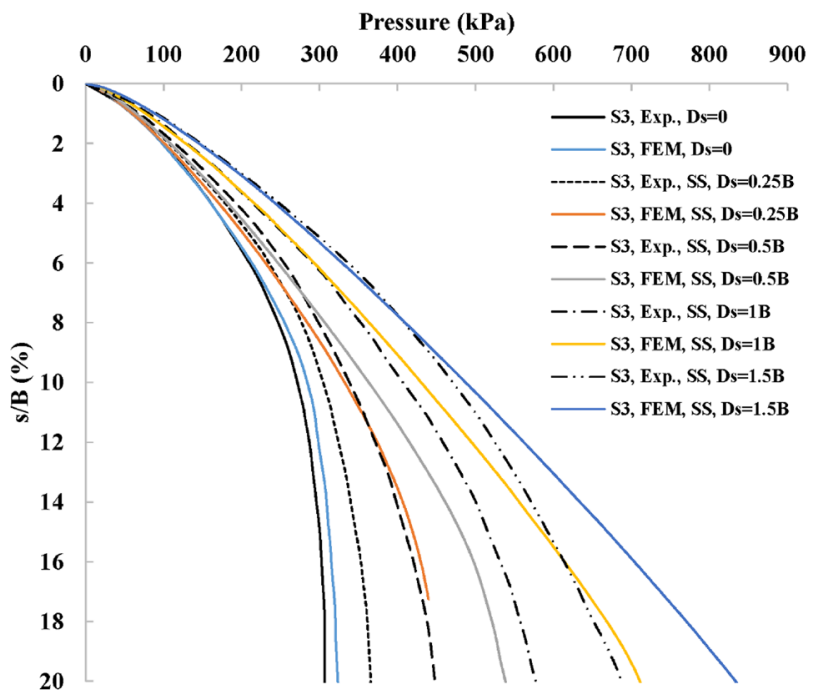

(c)

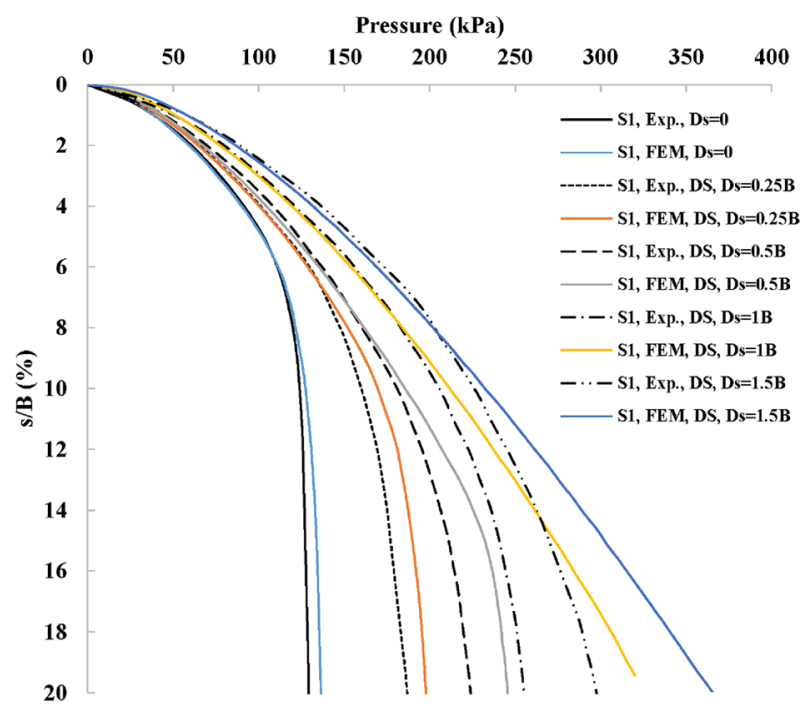

(d)

Fig. 8 Experimentally and numerically obtained pressure vs settlement-to-width ratio plot for the sands (S1, S2, S3) at normalised skirt depth of $0,0.25,0.5,1$ and 1.5 for singly skirted $(\mathbf{a}, \mathbf{b}, \mathbf{c})$ and doubly skirted $(\mathbf{d}, \mathbf{e}, \mathbf{f})$

normalised skirt depth. From Table 1, for the singly skirted hexagonal footings on three sands, the lowest improvement in bearing capacity was $9.11 \%$ at a $D_{s} / B=0.25$, while the highest improvement was $57.67 \%$ corresponding to $D_{S} / B=1.50$. The lowest improvement in bearing capacity was $11.73 \%$ at a $D_{s} / B=0.25$, while the highest improvement was $56.90 \%$, corresponding to $D_{s} / B=1.50$ for the doubly skirted hexagonal footings as evident from Table 1. Comparing the results of singly skirted and doubly skirted hexagonal footing as shown in Tables 1 and 2, it is evident that the percentage improvements in general for the doubly skirted hexagonal footing were marginally higher in comparison with the singly skirted hexagonal footing at all normalised skirt depths as well as for all the three sands. It means that double-skirt provision marginally benefits from improved bearing capacity compared to singly skirted footings. Analysis of Tables 1 and 2, further, shows that the numerically obtained bearing capacity for singly and doubly skirted hexagonal footings was comparable with the one obtained experimentally on all the three sands. A close examination of Tables 1 and 2 reveals that the bearing capacity also increases as the normalised skirt depth rises for both singly and doubly skirted hexagonal footings. Similar findings were made based on the experimental study of conventional skirted square footing $[4,6$, 20] in the literature. A close examination of Tables 1 and 2 


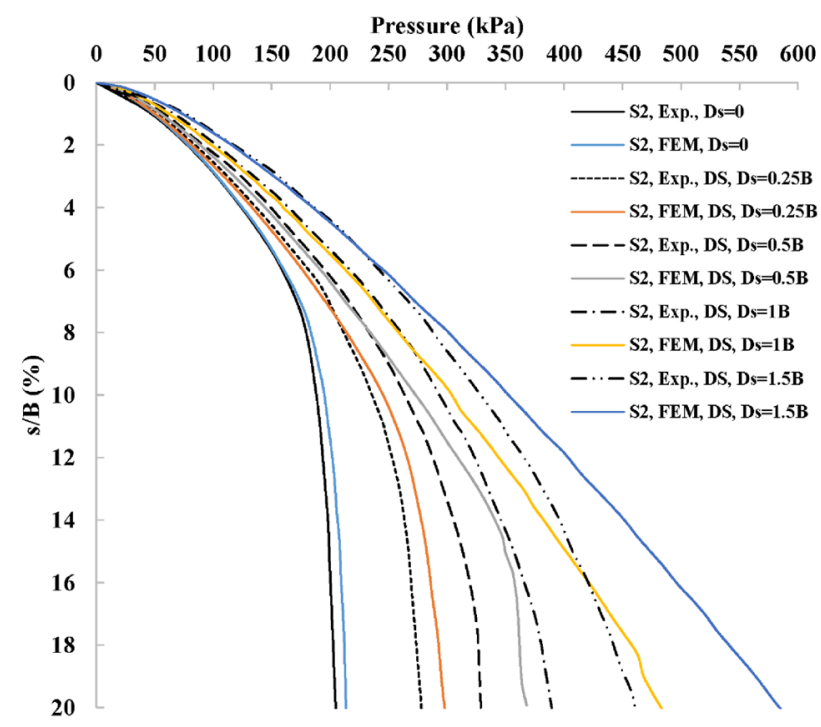

(e)

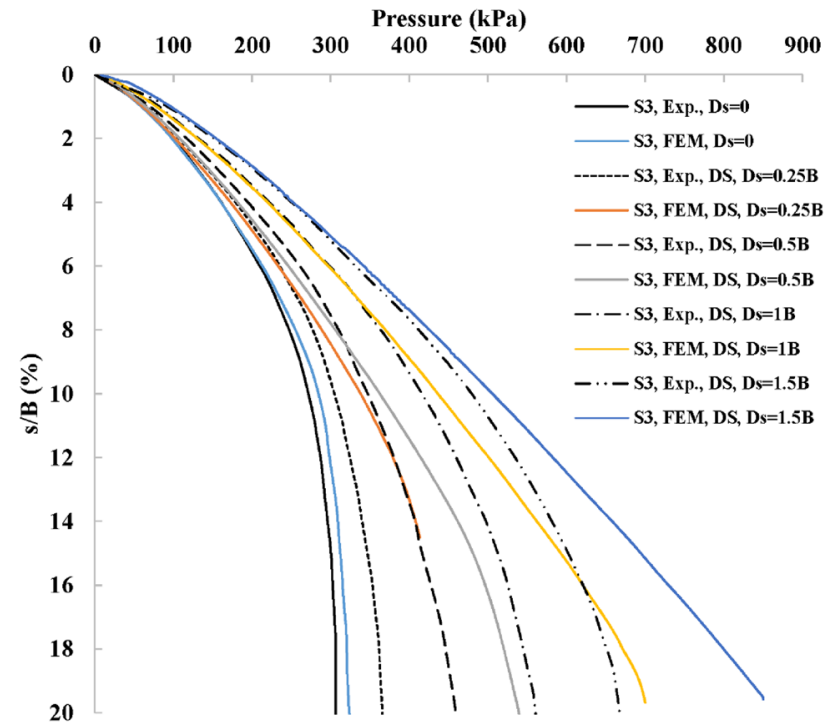

(f)

Fig. 8 (continued)

reveals that the bearing capacity obtained experimentally and numerically at different normalised skirt depths for the unskirted, singly and doubly skirted hexagonal footings falls within the $\pm 1 \%$. The minimum and maximum deviation in the bearing capacity obtained experimentally from the one obtained numerically was therefore about $1 \%$ and $6 \%$, respectively, with an average deviation of $1 \%$ for all the hexagonal footings. This can be concluded, therefore, that experimental results confirm the results obtained numerically and can be used as the basis for determining the gain from skirt use.

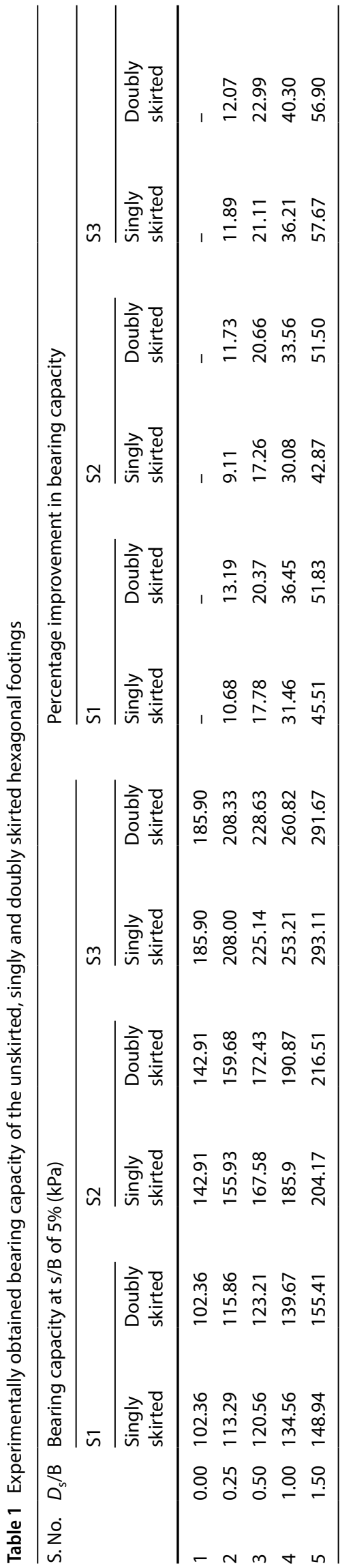

SN Applied Sciences 


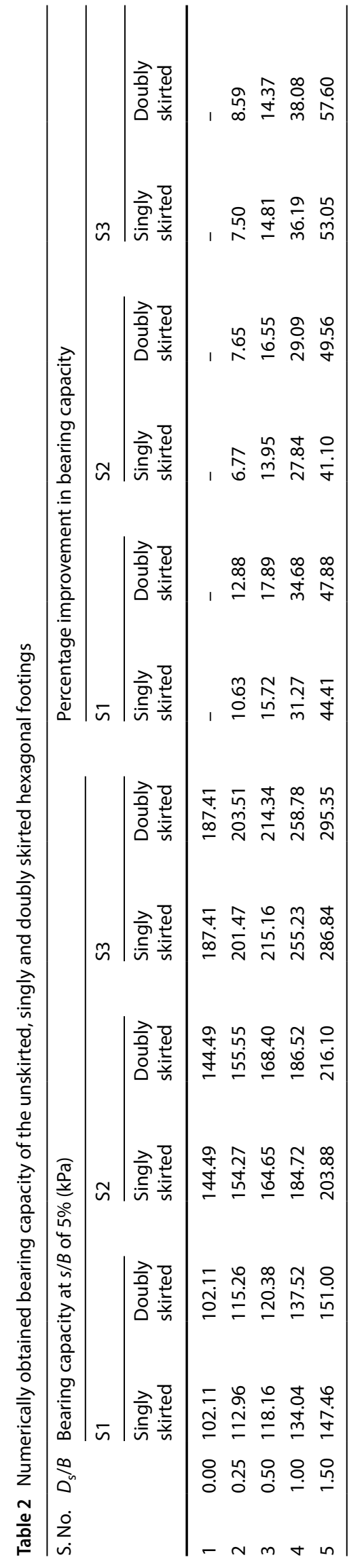

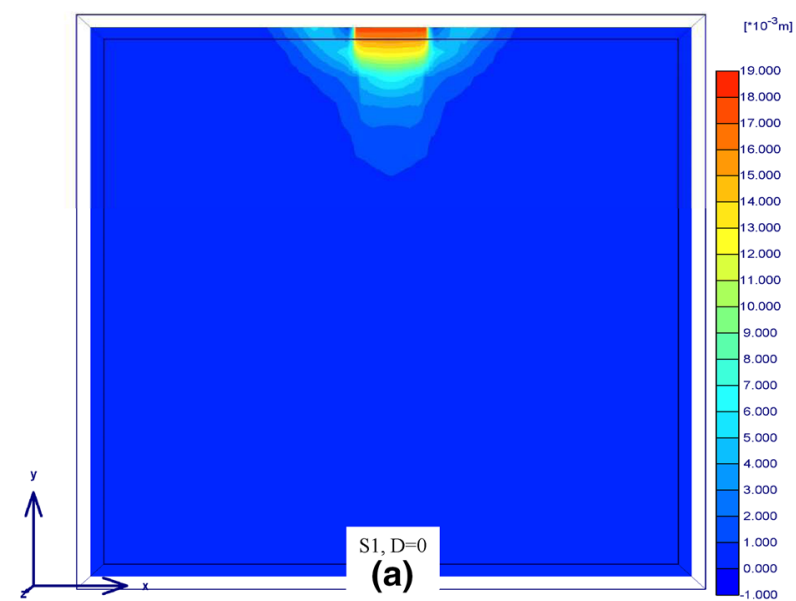
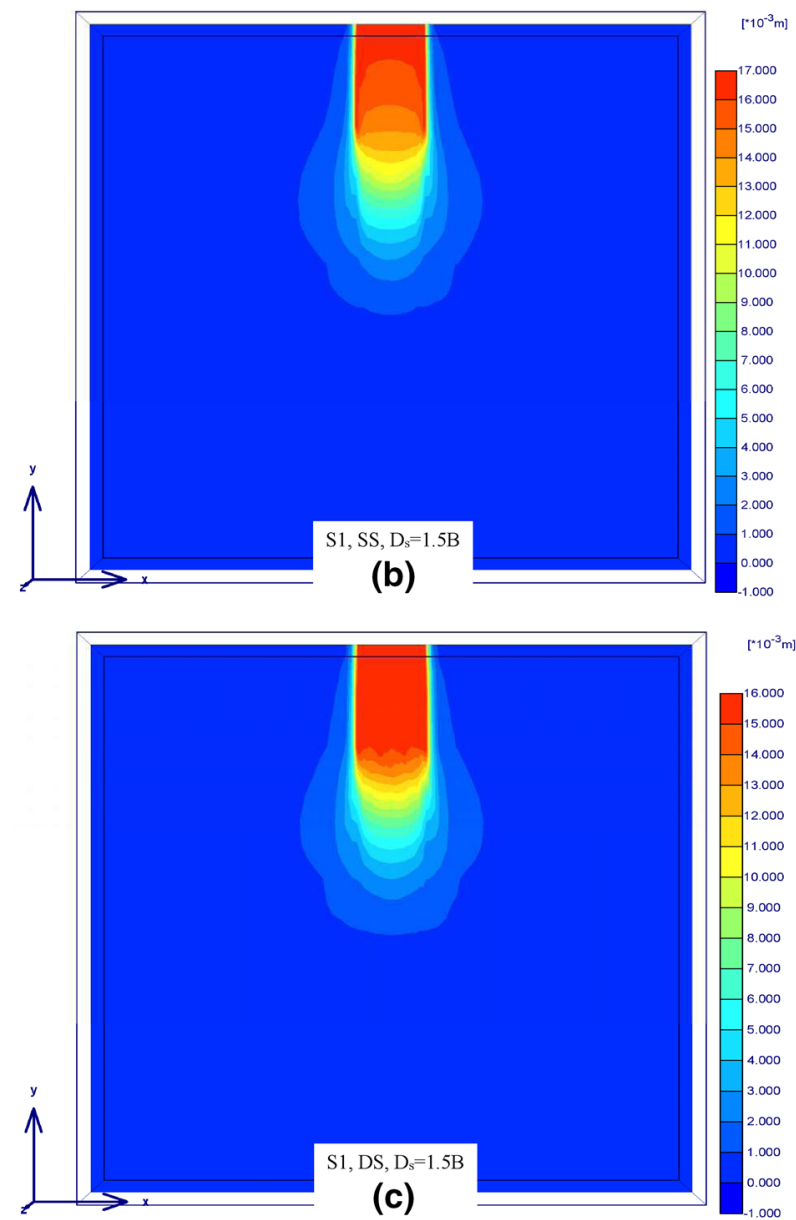

Fig. 9 Failure pattern of the hexagonal singly skirted footing on sand $\mathrm{S} 1(\mathbf{a}, \mathbf{b}, \mathbf{c})$ at a skirt depth of $0 \mathrm{~B}, 1.5 \mathrm{~B}$ (singly skirted) and 1.5B (doubly skirted)

\subsection{Failure patterns}

Figures 9,10 and 11 for sands S1, S2 and S3, respectively, show the typical pattern of failure developed for singly and doubly skirted hexagonal footings corresponding to a skirt depth of $O B$ and 1.5B. These failure patterns show the 

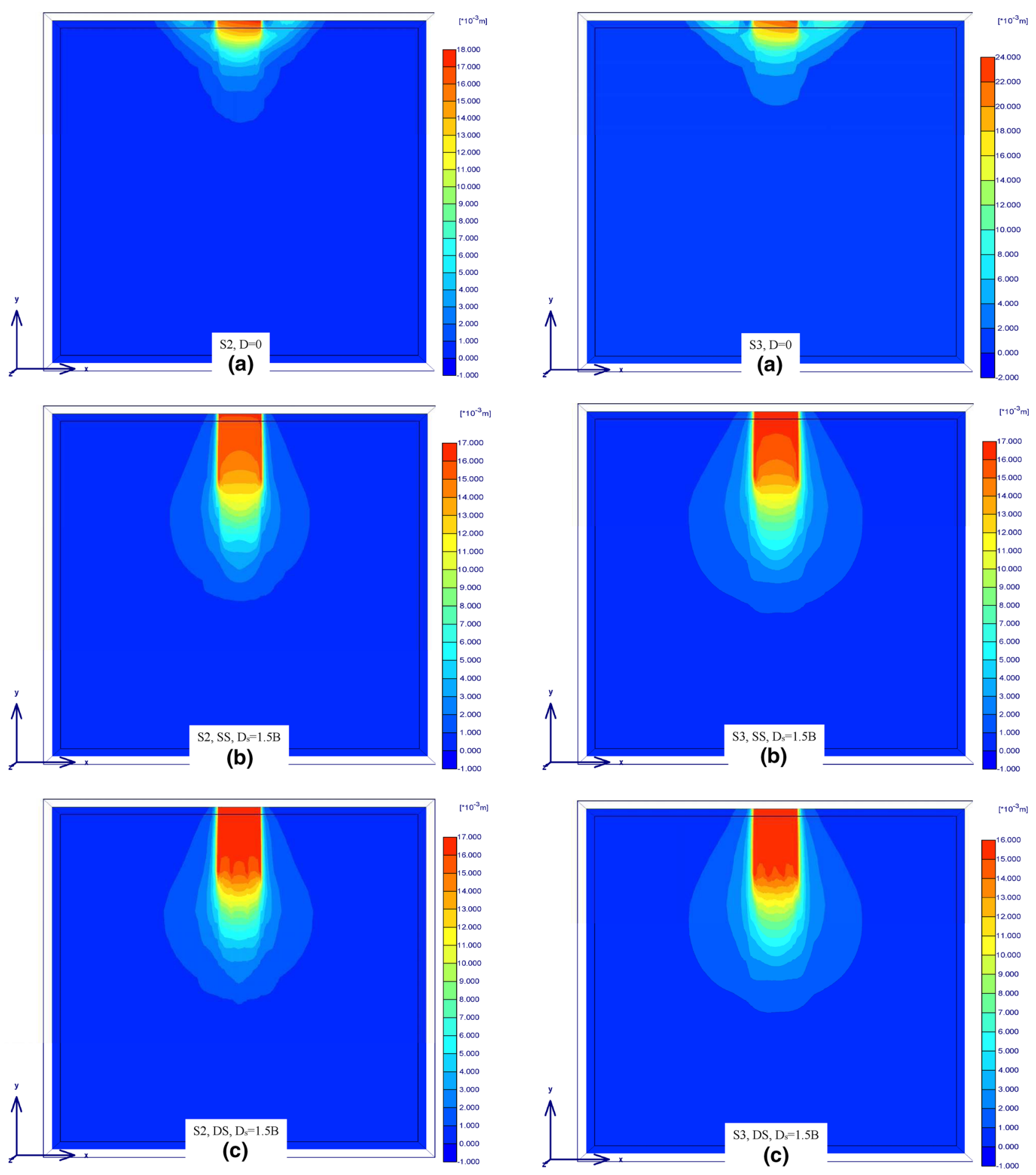

Fig. 10 Failure pattern of the hexagonal singly skirted footing on sand $\mathrm{S} 2(\mathbf{a}, \mathbf{b}, \mathbf{c})$ at a skirt depth of $\mathrm{OB}, 1.5 \mathrm{~B}$ (singly skirted) and 1.5B (doubly skirted)

total contour of the displacement, and their importance is to assess the actual displacement under the load. This type of information is required in order to verify the vertical settlement in the footing design within the acceptable limits

Fig. 11 Failure pattern of the hexagonal singly skirted footing on sand S3 $(\mathbf{a}, \mathbf{b}, \mathbf{c})$ at a skirt depth of $\mathrm{OB}, 1.5 \mathrm{~B}$ (singly skirted) and 1.5B (doubly skirted)

or not under the load. Analysis of these figures reveals that the isobar distance for sand S3 is greater than for sands S2 and $\mathrm{S} 1$ at a $0.5 B$ and $1.5 B$ skirt depth, respectively, indicating a higher bearing capacity for footing on sand S3. In 
Table 3 Comparison of dimensionless ultimate bearing capacity of hexagonal footing with the literature

\begin{tabular}{lllllll}
\hline Sands & \multicolumn{2}{l}{ Dimensionless ultimate bearing capacity $\left(q_{\mathrm{u}} / \gamma B\right)$} & & \\
\cline { 2 - 6 } & $\begin{array}{l}\text { Unskirted hex- } \\
\text { agonal footing }\end{array}$ & Meyerhof [28] & Vesic [29] & IS 6403 [30] & \multicolumn{2}{l}{ Terzaghi [31] } \\
\cline { 3 - 7 } & 88.97 & 30.58 & 19.44 & 18.92 & Square & Circular \\
\hline S1 & 124.22 & 56.56 & 32.26 & 24.29 & 29.34 & 13.45 \\
S2 & 161.59 & 102.71 & 52.39 & 38.42 & 45.40 & 35.98 \\
S3 & & & & & &
\end{tabular}

addition, the analysis of these figures indicates that the pattern of failure remained well established within the selected lateral and vertical distance for the unskirted, singly and doubly skirted hexagonal footings corresponding to a skirt depth of $O B, 0.5 B$ and 1.5B. This means it was enough for the chosen problem domain. Similar results for the failure patterns and for all the three sands used in this investigation were found at other skirt depths. The insights gained from the above study on the failure pattern will be useful for developing analytical solutions.

\subsection{Comparison with literature}

The present experimental results related to the ultimate bearing capacity of the hexagonal footing without skirt were compared with the well-established bearing capacity formulae [28-31]. To find out the bearing capacity of footing in accordance with these formulae, a triaxial friction angle of the three sands (S1, S2 and S3) was used. The relevant comparison of the dimensionless ultimate bearing capacity is provided in Table 3. From this table, it can be seen that the experimentally obtained dimensionless ultimate bearing capacity in present case was higher than those predicted by formulae's for all the three sands ( $\mathrm{S} 1, \mathrm{~S} 2$ and S3). This was perhaps due to higher mobilised friction in test on account of the dilation of the three sands, which was more significant at low stress level and slight localised densification of the sands nearby the footing due to the load application. This observation was on lines similar to that reported by Khatri et al. [12] with regard to square and rectangular footings on sand.

\section{Conclusions}

The experimental and numerical analysis on three sands of unskirted, singly and doubly skirted hexagonal footings subjected to vertical concentric load is investigated. A series of tests were conducted in a test tank and numerical analysis performed to assess the unskirted, singly and doubly skirted hexagonal footings on three sands. From "Results and discussion" section, the following conclusions are drawn:
- The numerically obtained bearing capacity was comparable to the one obtained experimentally for the hexagonal footings on sands (S1, S2 and S3).

- For the skirted hexagonal footings on sand $S 3$, the bearing capacity was higher followed by sands $\mathrm{S} 2$ and S1.

- For the singly skirted hexagonal footings on three sands, the lowest improvement in bearing capacity was $9.11 \%$ at a $D_{s} / B=0.25$, while the highest improvement was $57.67 \%$, corresponding to $D_{s} / B=1.50$.

- The lowest improvement in bearing capacity was $11.73 \%$ at a $D_{s} / B=0.25$, while the highest improvement was $56.90 \%$, corresponding to $D_{s} / B=1.50$ for the doubly skirted hexagonal footings.

- Doubly skirted arrangement marginally increases bearing capacity relative to singly skirted hexagonal footings.

- The findings of the tests confirmed the numerical results with an average deviation of $1 \%$.

- The failure pattern generated supports the observations of the unskirted, singly and doubly skirted hexagonal footings with regard to the bearing capacity on three sands.

Acknowledgements The authors would like to express their special thanks of gratitude to Central Building Research Institute (CSIR-CBRI), Roorkee, for providing us the opportunity to utilise the Plaxis-3D software.

\section{Compliance with ethical standards}

Conflict of interest The authors have no conflict of interest with anyone related to the material presented in the paper.

\section{References}

1. Jaiswal U, Sengupta P (2017) Seismic performance of reinforced concrete buildings with plan asymmetry. Int J Emerg Technol Adv Eng 7(2):246-251

2. Davarci B, Ornek M, Turedi Y (2014) Analysis of multi-edge footings rested on loose and dense sand. Period Politech Civ Eng 58(4):355-370

3. Ghazavi M, Mokhtari S (2008) Numerical investigation of loadsettlement characteristics of multi-edge shallow foundations. In: 
The 12th international conference of international association for computer methods and advances in geomechanics, Goa, India, pp 3344-3351

4. Gnananandarao T, Khatri VN, Dutta RK (2018) Performance of multi-edge skirted footings resting on sand. Indian Geotech J 48(3):510-519. https://doi.org/10.1007/s40098-017-0270-6

5. Al-Aghbari MY, Mohamedzein YE-A (2004) Bearing capacity of strip foundations with structural skirts. Geotech Geol Eng 22(1):43-57. https://doi.org/10.1023/B:GEGE.0000013997.79473 .e0

6. Khatri VN, Kumar J (2019) Finite-element limit analysis of strip and circular skirted footings on sand. Int J Geomech 19(3):06019001

7. Al-Aghbari MY, Mohamedzein YEA, Al-N Hammad (2019) Potential use of structural skirts towards improving the bearing capacity of shallow footings exposed to inclined loadings. Int J Geotech Eng. https://doi.org/10.1080/19386362.2019.1617477

8. Al-Aghbari MY, Dutta RK (2008) Performance of square footing with structural skirt resting on sand. Geomech Geoeng 3(4):271-277. https://doi.org/10.1080/17486020802509393

9. Eid HT, Alansari OA, Odeh AM, Nasr MN, Sadek HA (2009) Comparative study on the behaviour of square foundations resting on confined sand. Can Geotech J 46:438-453. https://doi. org/10.1139/T08-134

10. Eid HT (2013) Bearing capacity and settlement of skirted shallow foundations on sand. Int J Geomech 13(5):645-652. https://doi. org/10.1061/(ASCE)GM.1943-5622.0000237

11. Rezaei H, Nazir R, Momeni E (2016) Bearing capacity of thinwalled shallow foundations: an experimental and artificial intelligence-based study. J Zehjiang Univ Sci A Appl Phys Eng 17(4):273-285. https://doi.org/10.1631/jzus.A1500033

12. Khatri VN, Debbarma SP, Dutta RK, Mohanty B (2017) Pressuresettlement behaviour of square and rectangular skirted footings resting on sand. Geomech Eng 12(4):689-705. https://doi. org/10.12989/gae.2017.12.4.689

13. El Sawwaf M, Nazer A (2005) Behaviour of circular footings resting on confined granular soil. J Geotech Geoenviron Eng 131(3):359-366. https://doi.org/10.1061/(ASCE)1090-0241

14. Al-Aghbari MY (2006) Improving the performance of circular foundations using structural skirts. Ground Improv 10(3):125-132

15. Villalobos $F$ (2007) Bearing capacity of skirted foundations in sand. VI Congreso chileno de Geotecnia, SOCHIGE Valparaiso

16. Al-Aghbari MY (2007) Settlement of shallow circular foundations with structural skirts resting on sand. J Eng Res 4(1):11-16. https ://doi.org/10.24200/tjer.vol4iss1pp11-16
17. El Wakil AZ (2010) Horizontal capacity of skirted circular shallow footings on sand. Alex Eng J 49:379-385. https://doi. org/10.1016/j.aej.2010.07.003

18. El Wakil AZ (2013) Bearing capacity of skirt circular footing on sand. Alex Eng J 52:359-364. https://doi.org/10.1016/j. aej.2013.01.007

19. El-Saied AE, Saleh NM, El-Mashad ME (2015) Behaviour of circular footing resting on laterally confined granular reinforced soil. Hous Build Natl Res Center J 11(2):240-245

20. Sajjad G, Masoud M (2019) Study of the behaviour of skirted shallow foundations resting on sand. Int J Phys Model Geotech 18(3):1-14. https://doi.org/10.1680/jphmg.16.00079

21. Rezazadeh S, Eslami A (2018) Bearing capacity of semi-deep skirted foundations on clay using stress characteristics and finite element analyses. Mar Georesour Geotechnol 36(6):625-639. https://doi.org/10.1080/1064119X.2017.1361488

22. Al-Aghbari MY, Mohamedzein YEA (2018) The use of skirts to improve the performance of a footing in sand. Int J Geotech Eng. https://doi.org/10.1080/19386362.2018.1429702

23. Mahmood MR, Fattah MY, Khalaf A (2019) Experimental investigation on the bearing capacity of skirted foundations on submerged gypseous soil. Mar Georesour Geotechnol. https://doi. org/10.1080/1064119X.2019.1656311

24. Prasanth T, Kumar PR (2017) A study on load carrying capacity of skirted foundation on sand. Int J Sci Res 6(6):2231-2235

25. Chakraborty D, Kumar J (2013) Dependency of Ny on footing diameter for circular footings. Soils Found 53(1):173-180

26. Tang C, Phoon KK, Toh KC (2014) Effect of footing width on $\mathrm{Ny}$ and failure envelope of eccentrically and obliquely loaded strip footings on sand. Can Geotech J 52(6):694-707

27. Acharyya R, Dey A (2015) Site characterization and bearing capacity estimation for a school building located on hillslope. In: Indian geotechnical conference, Pune, Maharashtra, India

28. Meyerhof GG (1963) Some recent research on bearing capacity of foundations. Can Geotech J 1:16-26

29. Vesic AS (1973) Analysis of ultimate loads of shallow foundations. J Soil Mech Found Eng 99:45-73

30. IS 6403 (1981) Determination of bearing capacity of shallow foundation. Bureau of Indian Standard, New Delhi

31. Terzaghi K (1943) Theoretical soil mechanics. Wiley, New York

Publisher's Note Springer Nature remains neutral with regard to jurisdictional claims in published maps and institutional affiliations. 